\title{
Sistema de selección electrónico de café excelso basado en el color mediante procesamiento de imágenes
}

\section{An automatic sorting system based on coffee-grain color identification for the "excelso" presentation using image processing}

\author{
Ilber Adonayt Ruge Ruge \\ Ingeniero electrónico, magíster en Ingeniería de Control Industrial. Docente de \\ la Universidad de Cundinamarca. Fusagasugá, Colombia. \\ Contacto:iruge@mail.unicundi.edu.co
}

\section{Arthur Steven Pinzon Arias}

Ingeniero electrónico. Investigador de la Universidad de Cundinamarca. Fusagasugá, Colombia. Contacto: arthurspinzon@hotmail.com

\section{Daniel Enrique Moreno Ochoa}

Ingeniero electrónico. Investigador de la Universidad de Cundinamarca. Fusagasugá, Colombia. Contacto: tiochapupo@hotmail.com

Fecha de recepción: 9 de noviembre de 2011

Clasificación del artículo: Investigación

Fecha de aceptación: 28 de agosto de 2012

Financiamiento: Universidad de Cundinamarca

Palabras clave: café excelso, procesamiento digital de imágenes, selección, umbralización multinivel.

Key words: excelso coffee, digital image processing, screening, multilevel threshold.

\section{RESUMEN}

En este artículo se describe brevemente una aplicación del procesamiento de imágenes digitales mediante la técnica de umbralización multinivel, que pretende dar solución a una problemática existente en las fincas cafeteras de baja y mediana producción, debido a que estas fincas no cuentan con un medio más adecuado en costo y producción para la selección del café en la presentación excelso de una manera automática y se 


\section{investigación}

ven en la necesidad de seleccionar este producto de manera manual.

\section{ABSTRACT}

This paper describes an application of digital-image processing using multi-threshold techniques intended to solve an existing problem at the lowand medium-production coffee farms. The motivation behind this study is that these farms do not have a suitable procedure (in terms of production and cost) to perform coffee selection ("excelso" coffee) automatically and have to resort to selecting this product manually.

\section{INTRODUCCIÓN}

En los procesos de globalización, con todas las teorías comerciales, se ha generado un interés prioritario con respecto a la calidad de los recursos exportables, que exige a los productores de café adaptarse a procesos y productos regidos bajo estándares modernos. En donde la competencia, entre los países productores, obliga a cada uno de ellos a buscar ventajas competitivas haciendo uso de sus facultades intelectuales y tecnológicas [1].

Debido a las apreciaciones manifestadas anteriormente, es necesario hacer uso de recursos tecnológicos actuales que logren dar solución a problemáticas reales, como los procesos de selección para el café, en tanto que, los consumidores han aprendido a valorar las buenas características de calidad de los cafés especiales, transformando así la práctica cafetera en un actividad minuciosa.

En la actualidad, al abordar la problemática de una manera particular con respecto a la producción de café de buena calidad, se requiere el desarrollo de procesos específicos y precisos, como el de la selección del café tipo excelso, al cual se le han encontrado defectos; algunos de ellos son observables en los granos y afectan las características del café, como: el aroma, el sabor y el aspecto de la bebida.
Por tal motivo, este articulo propone una solución para facilitar la remoción de los defectos de los granos de café en la presentación excelso, de una manera relativamente económica y más ajustada a producciones pequeñas para fincas cafeteras de baja y mediana producción, haciendo uso de los beneficios del procesamiento de imágenes digitales, que permiten, mediante la aplicación de algoritmos, identificar las características observables de los granos y posteriormente remover los granos defectuosos del café mediante la acción de un sistema mecánico controlado.

\section{METODOLOGÍA}

La tabla 1 enumera los defectos y se muestra la incidencia de los mismos en la calidad del café en la presentación excelso [2].

El café, de acuerdo a los requerimientos de calidad en los mercados nacionales y extranjeros, debe contar con las mejores condiciones en cuanto a sabor, aroma y aspecto. Estas características están estrechamente ligadas a las condiciones observables en los granos de café, que son conocidas desde hace tiempo, y se realizan de manera tradicional, en la mayoría de las fincas cafeteras, con procesos de selección manual buscando extraer los granos que tienen incidencia negativa en el producto final y que cuentan con un color 
Tabla 1. Incidencia de los defectos del café excelso.

\begin{tabular}{|c|c|c|c|}
\hline \multirow[t]{2}{*}{ Defectos del café } & \multicolumn{3}{|c|}{$\begin{array}{c}\text { Incidencia } \\
\text { de la calidad del café }\end{array}$} \\
\hline & 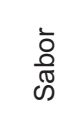 & $\begin{array}{l}\frac{\mathbb{Z}}{\varepsilon} \\
\frac{0}{<}\end{array}$ & $\begin{array}{l}0 \\
\frac{0}{0} \\
\frac{0}{0} \\
\frac{0}{0}\end{array}$ \\
\hline \multicolumn{4}{|l|}{ 1.Negro total o parcial } \\
\hline \multicolumn{4}{|l|}{ 2.Cardenillo } \\
\hline \multicolumn{4}{|l|}{ 3.Vinagre o parcialmente vinagre } \\
\hline \multicolumn{4}{|l|}{ 4.Cristalizado } \\
\hline \multicolumn{4}{|l|}{ 5.Decolorado veteado } \\
\hline \multicolumn{4}{|l|}{ 6.Decolorado reposado } \\
\hline \multicolumn{4}{|l|}{ 7.Ambar o mantequillo } \\
\hline \multicolumn{4}{|l|}{ 8.Decolorado sobresecado } \\
\hline \multicolumn{4}{|l|}{ 9.Mordido o cortado } \\
\hline \multicolumn{4}{|l|}{ 10.Picado por insectos } \\
\hline \multicolumn{4}{|l|}{ 11.Averanado o arrugado } \\
\hline \multicolumn{4}{|l|}{ 12.Inmaduro y/o paloteado } \\
\hline \multicolumn{4}{|l|}{ 13. Aplastado } \\
\hline \multicolumn{4}{|l|}{ 14. Flojo } \\
\hline Puede afectar & & ecta & \\
\hline
\end{tabular}

Fuente: Federación Nacional de Cafeteros de Colombia, Aprenda a vender su café.

inadecuado. Un producto de color uniforme posee un aspecto más atractivo, incrementando su valor, calidad y evitando las aspectos indeseables de granos defectuosos en las características de una buena bebida.

Tomando como característica principal el color del grano, la figura 1 muestra los procesos propuestos a realizar para la selección del café excelso mediante la identificación por color del grano.

La dosificación de los granos de café es la etapa inicial del sistema selector. Su función es recibir los granos de café sin seleccionar y ubicarlos uno a uno para la etapa de captura de imagen.

Para la recepción del grano de café, sin seleccionar, se dispone de una tolva receptora metálica.

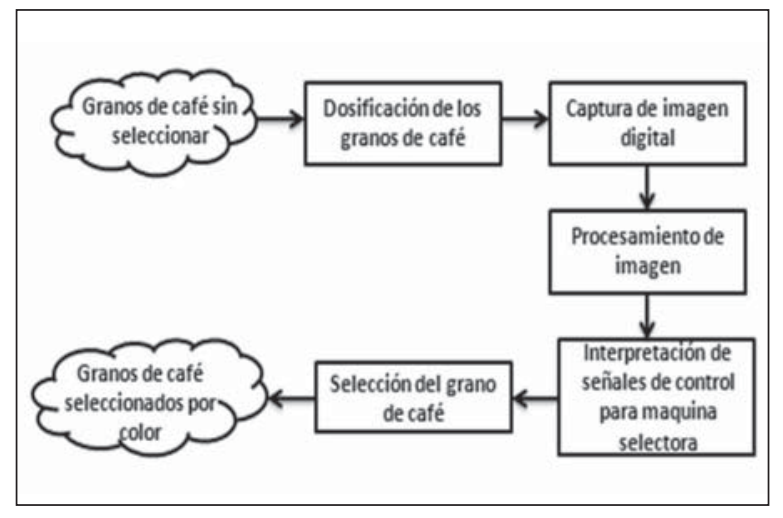

Figura 1. Proceso de selección de café.

Fuente: elaboración propia

En la etapa de ubicación del grano de café y la realización de la captura de imagen, se dispone de un sistema de disco con agujeros que, al rotar, succiona los granos y finalmente lo aloja en la cámara de procesamiento de imagen ver figura 2 .

El sistema de captura de imagen digital está constituido por una caja herméticamente sellada con iluminación constante, que facilita las condiciones adecuadas para la toma de imágenes con una cámara digital y una compuerta que permite la salida de los granos luego de ser evaluados. El lente de la cámara fotográfica se encuentra posicionado a $7 \mathrm{~cm}$ de la base de disposición del grano debido que ésta es la distancia de foco de la cámara.

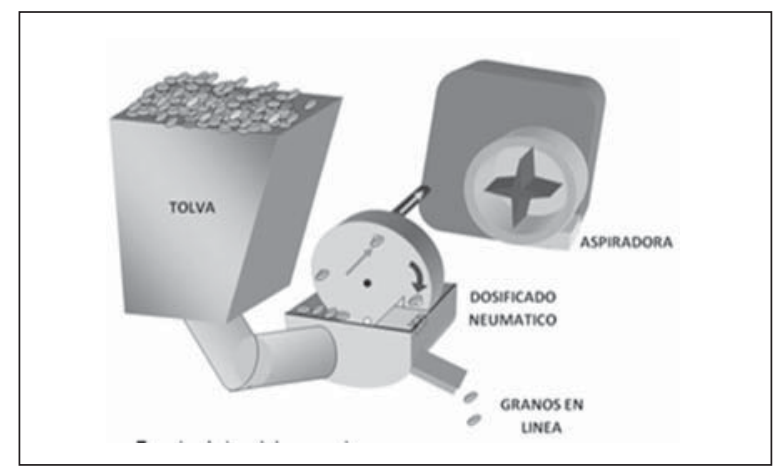

Figura 2. Tolva y sistema de dosificación. Fuente: elaboración propia 


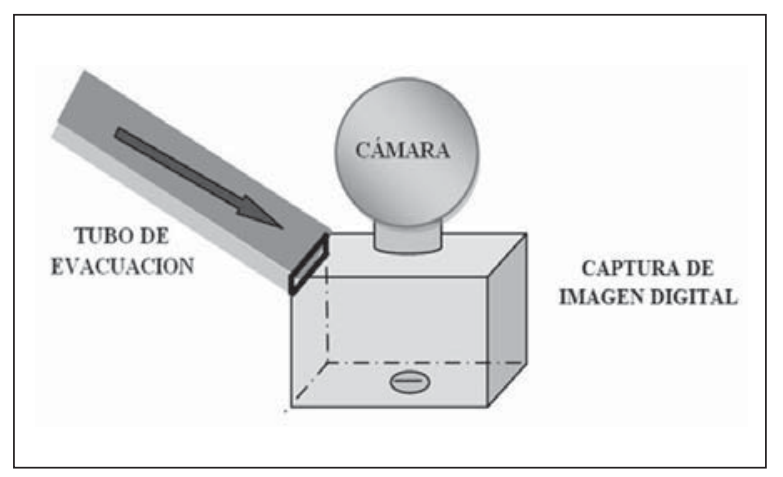

Figura 3. Sistema de captura de imagen del grano. Fuente: elaboración propia

Las imágenes son adquiridas con una cámara digital, que adquiere imágenes de $320 \times 240$, equivalente a 76.800 pixeles; esta resolución se consideró adecuada de acuerdo a pruebas realizadas con diferentes cámaras ejecutando el algoritmo de control; observando que, para resoluciones superiores, el tiempo de ejecución era muy elevado o se desbordaba la memoria del computador; debido a las características bajas de los equipos de computo figura 3 .

Posteriormente, se determinó el fondo más adecuado para las paredes del ambiente de captura de imágenes figura 4 , haciendo pruebas con diferentes colores, variando la luminosidad y observando cuál ofrecía las mejores condiciones para la captura de las imágenes en cuanto a brillo, tono y color; teniendo en cuenta las características de los granos.

Se determinó que el fondo que mejor se acondicionaba a los granos de café es el blanco, al ofre-

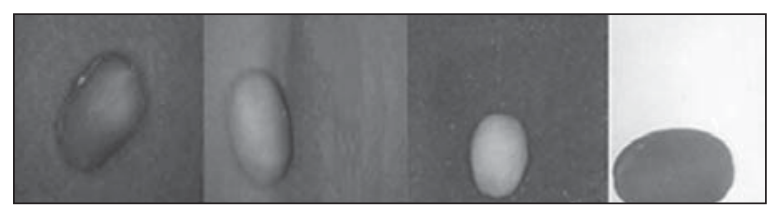

Figura 4. Pruebas de fondo para toma de imagen a procesar.

Fuente: elaboración propia

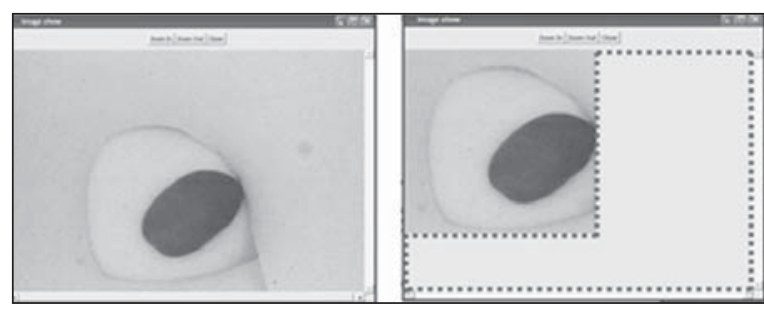

Figura 5. Imagen original y recortada.

Fuente: elaboración propia

cer una imagen más real y una mayor diferencia entre el fondo y el grano.

El sistema de procesamiento digital de señal emplea una computadora con un programa creado en SCILAB, que permite coordinar las actividades del sistema selector de manera general, encargándose de recibir la información proporcionada por una cámara digital para, posteriormente, procesarla; determinando presencia y estado de los granos de café dentro de un ambiente controlado, con el fin de accionar dispositivos eléctricos en la parte mecánica con ayuda del bloque de adecuación de señales.

Luego de realizar el proceso de captura de la imagen, el paso siguiente es recortar la imagen para disminuir su tamaño figura 5 , teniendo en cuenta que hay zonas de la fotografía tomadas por la cámara que nunca tendrán presencia de grano, debido a que por condiciones mecánicas los granos no logran posicionarse en estos lugares.

Este paso logra eliminar el 63,54\% de la imagen aumentando en una proporción similar el rendimiento del algoritmo debido a que el análisis del algoritmo se hace pixel a pixel como en las ecuaciones (1), (2), (3) y (4).

$$
\begin{gathered}
\% \text { Retirado }=\frac{\text { Area Inicial }- \text { Area Final }}{\text { Area Inicial }} * 100 \\
\% \text { Retirado }=\frac{(m * n)-(r * q)}{(m * n)} * 100
\end{gathered}
$$




$$
\begin{gathered}
\% \text { Retirado }=\frac{(320 * 240)-(160 * 175)}{(320 * 240)} * 100 \\
\% \text { Retirado }=63.54
\end{gathered}
$$

Donde $\mathrm{m}^{*} \mathrm{n}$ son las dimensiones en pixeles de la imagen inicial y $\mathrm{r}^{*} \mathrm{q}$ son las dimensiones de la imagen luego de ser recortada.

Con el fin de ahorrar tiempo computacional, se realizó una etapa de detección de grano, pues no tiene caso analizar completamente una imagen sin presencia de granos. Por consiguiente, esta parte del algoritmo de procesamiento se encarga de determinar la presencia del grano, en donde se hace un procesamiento con la imagen en tonos grises para determinar su presencia (figura. 6); para tal fin, inicialmente la imagen se pasa a escala de grises.

Luego se establece un umbral de 130, para este caso, el cual consiste en dar un límite para indicar las tonalidades que determinan los siguientes valores así: superiores o más claras, se asigna el valor de verdadero (T); inferiores o más oscuras, el de falso (F); teniendo en cuenta que una imagen a blanco y negro tiene valores de 0 a 255 . El proceso de transformar una imagen a valores

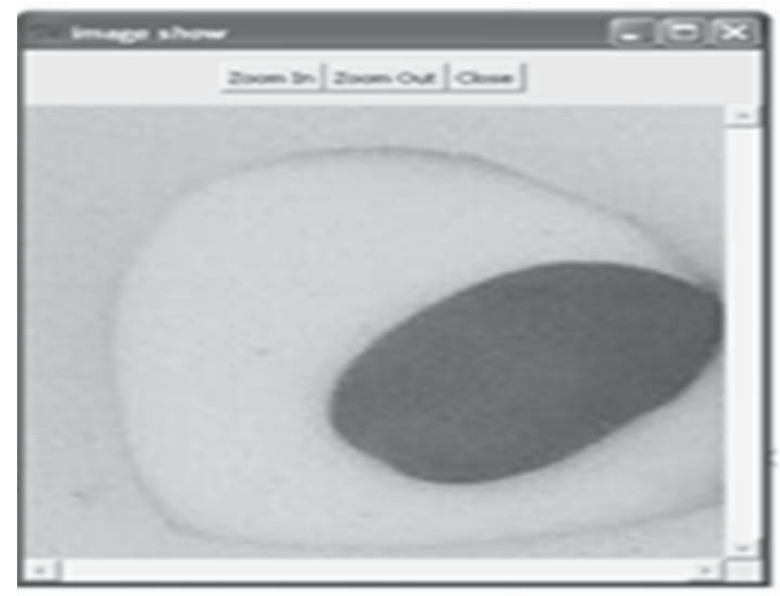

Figura 6. Imagen a escala de grises.

Fuente: elaboración propia

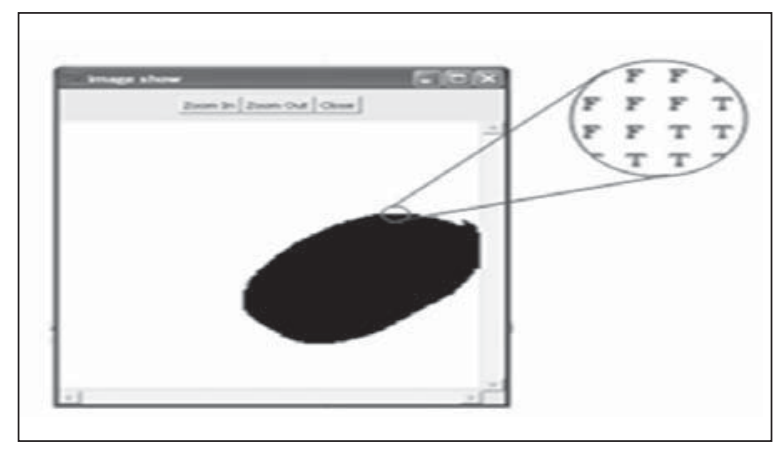

Figura 7. Imagen binarizada.

Fuente: elaboración propia

booleanos se le conoce como binarización, ver figura 7, debido a que la imagen toma valores binarios, permitiendo resaltar algunos objetos en la imagen, en este caso el grano, para determinar su presencia.

Luego, se realiza el histograma de la imagen binarizada ver figura 8 , que consiste en un conteo de pixeles y su respectiva representación en diagrama de barras [3] - [5].

Para una imagen con mínimos pixeles negros, se deduce que no hay presencia de granos de café y, en caso contrario, se determina que hay un grano presente y se continúa con el procesamiento de la imagen.

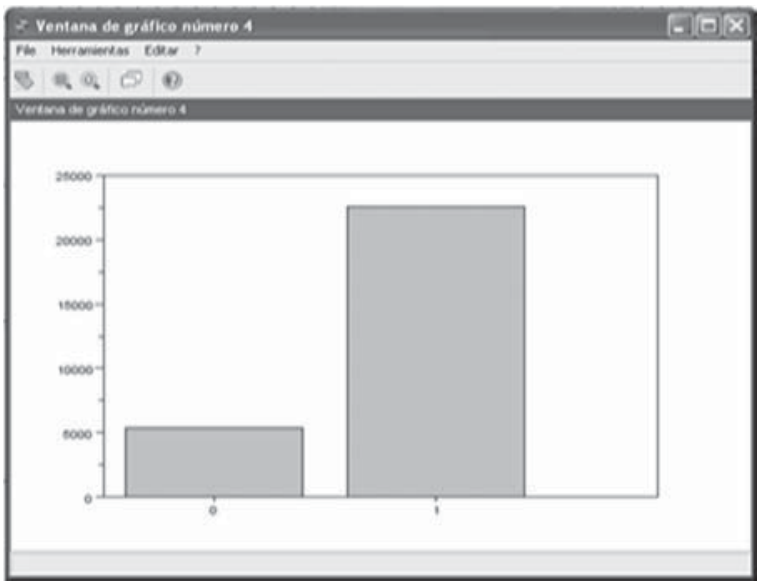

Figura 8. Histograma de la imagen binarizada. Fuente: elaboración propia 


\section{investigación}

Para la segmentación de una imagen a color se emplea la técnica de umbralización multinivel [5], debido a que se pueden establecer, con mayor precisión, rangos fijos y no dinámicos para la identificación de las áreas afectadas y aéreas buenas, sin confusión con otras zonas en la imagen. La solución que ofrece este sistema es identificar un color característico de los granos buenos que ya está predeterminado de acuerdo a información proporcionada por comercializadores del café.

Teniendo en cuenta otras consideraciones, las imágenes son analizadas en modelo de color RGB, al ser éste el estándar que manejan la mayoría de las cámaras digitales, lo que permite optimizar el programa de control en velocidad, pues no necesita realizar conversiones.

Otro aspecto de gran importancia en el uso del espacio de color RGB es su gran cantidad de tonalidades para cada color, que aporta mayor precisión en la formación de los grupos, evitando que se confundan lo colores entres sí dentro de los grupos.

Para la utilización del método de segmentación por umbralización multinivel, es necesario establecer grupos para cada área que se desee segmentar. A cada grupo hay que asignarle un rango mínimo y uno máximo, para cada componente RGB; es decir, para el rojo se le asigna un rango mínimo y otro máximo, del mismo modo con el verde y el azul; los valores de los rangos son los límites del conjunto que contiene los pixeles relacionados con el área analizada. Los rangos encontrados se emplean de la siguiente manera:

$($ Rmin $<$ Pixel $<$ Rmax) AND $($ Gmin $<$ Pixel $<$ Gmax) AND $\left(V_{\min }<\right.$ Pixel $<$ Vmax $)=$ GRU PO 1,

(Rmin2 $<$ Pixel $<$ Rmax2) AND (Gmin2 $<$ Pixel $<$ Gmax2)AND $(\operatorname{Vmin} 2<$ Pixe $<$ Vmax 2$)=$ GRUPO 2,
$($ RminN $<$ Pixel $<$ RmaxN) AND

$($ GminN $<$ Pixel $<$ GmaxN) AND

$(\mathrm{V} \min \mathrm{N}<$ Pixel $<\operatorname{VmaxN})=$ GRUPO N, ..

Entonces,

(GRUPO 1 OR GRUPO 2 OR GRUPO N, ...) = AREA SEGMENTADA

Los pasos mostrados anteriormente se deben ejecutar para cada área que se desee segmentar, para el caso tratado en este trabajo de investigación, sólo es necesario establecer tres áreas: fondo, área buena del grano y área mala del grano.

Los rangos de los grupos son tomados de manera experimental en las áreas de las imágenes que se desean segmentar, con la ayuda de un programa llamado IMLAB ver figura 9, el cual ofrece la posibilidad de tomar datos de los pixeles de cada área dando como resultado el valor en RGB de cada pixel y su coordenada.

Para segmentar las áreas de grano bueno se necesitó realizar un proceso igual al utilizado para el fondo, pero esta vez con la zona buena del grano.

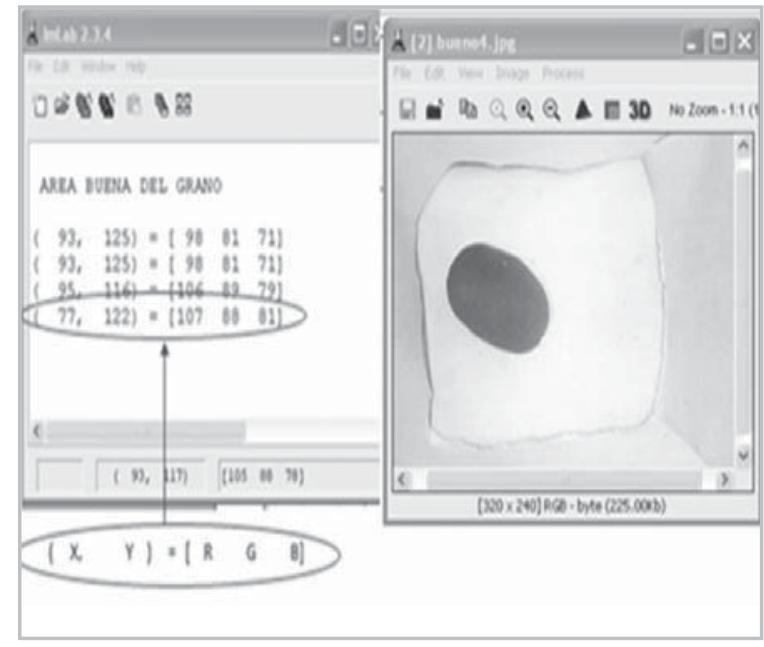

Figura 9. Obtención de valores RGB de la imagen a procesar con IMLAB.

Fuente: elaboración propia 


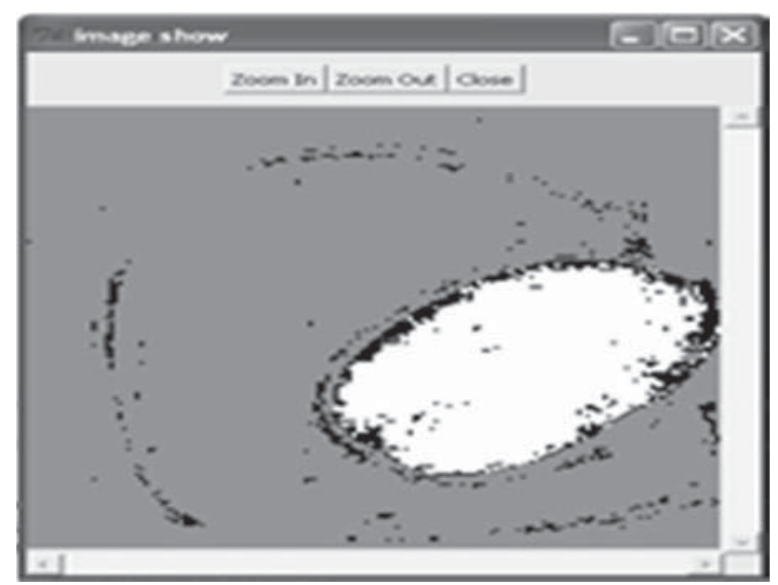

Figura 10. Segmentación de un grano de café bueno. Fuente: elaboración propia

Posteriormente, se segmenta, con IMLAB, la imagen con los datos obtenidos. Para la segmentación del grano (figura 10) se ha determinado qué: el gris queda al fondo, de blanco queda la parte buena, y de negro el ruido y la parte afectada.

Para quitar el ruido de la imagen se empleó un filtro Bottom Hat [5] - [7] (ver figura 11), el cual encaja matrices cuadradas dentro todos los elementos de la imagen y resalta aquellos que son más pequeños que la matriz estructurante. Para este caso se empleó una matriz de 6X6 pixeles.

Para el conteo de pixeles correspondientes al área buena del grano procesado, figura 12, se utilizó un histograma.

Con el histograma se determina si el grano es bueno o malo, de acuerdo a la cantidad de pixeles

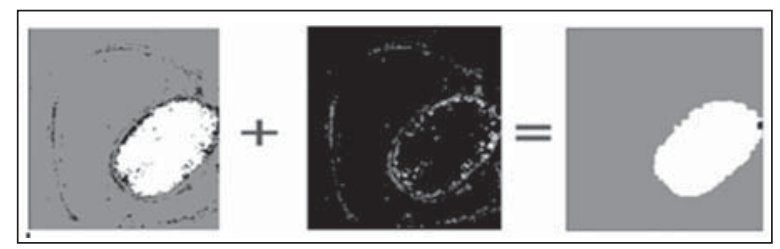

Figura 11. Proceso de filtrado con Botton Hat de una imagen.

Fuente: elaboración propia

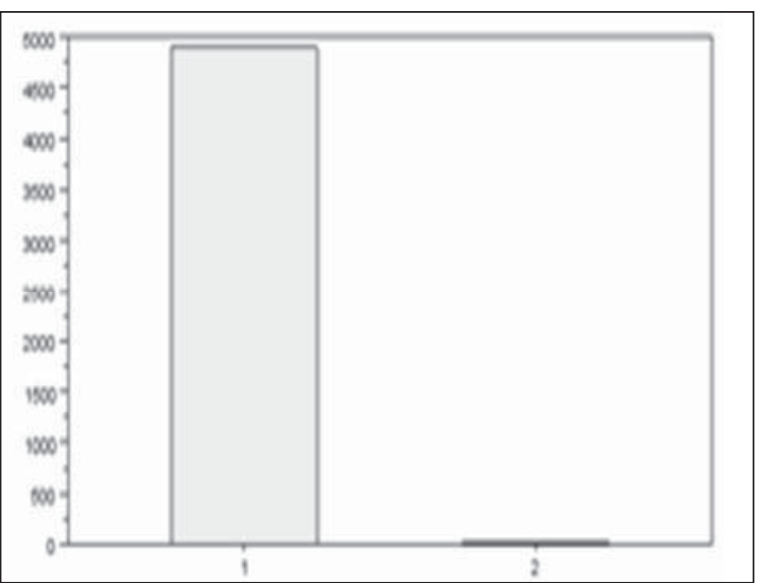

Figura 12. Histograma de la imagen de un grano bueno de café.

Fuente: elaboración propia

de cada área; con una serie de señales senoidales, a diferentes frecuencias, generadas por un computador y enviadas a través de la tarjeta de sonido hacia el microcontrolador, el cual determinará la acción que realizará el sistema selector de café.

- Activar dosificador $->120 \mathrm{~Hz}$.

- Grano Bueno -> 160Hz.

- Grano Malo -> 200Hz.

Para la selección del grano de café se conformó una estructura metálica de dos canales, los cuales direccionan el tipo de grano dependiendo de si es apto, o no, y una paleta selectora que dirige los granos según corresponda, ver figura 13 , de acuerdo a órdenes trasmitidas desde el computador. Esta etapa recibe las señales provenientes del microcontrolador.

Para la validación de los resultados entregados por el algoritmo de procesamiento, se sometieron a evaluación varios granos de café, con personas expertas en la selección de café tipo excelso de la Hacienda Cafetera California Viota en Cundinamarca, y al confrontar esta evaluación con los resultados entregados por el sistema de pro- 


\section{investigación}

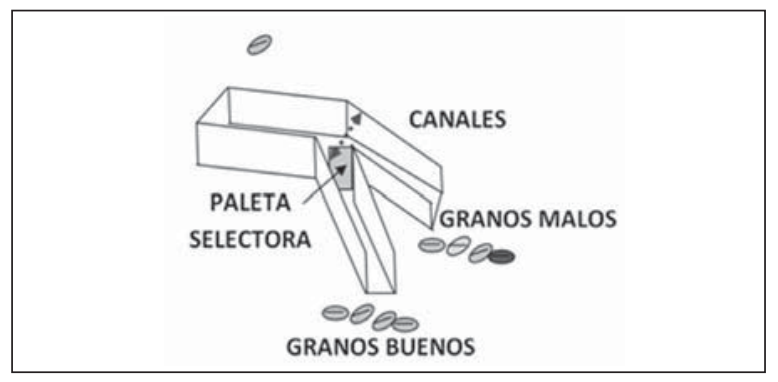

Figura 13. Selección de los granos de café.

Fuente: elaboración propia

cesamiento de imagen, se logró determinar que un grano bueno se puede catalogar como aquel que tiene menos de 1000 pixeles de área mala o dañada de grano evaluado.

\section{RESULTADOS}

La figura 14 muestra un diagrama de la maquina selectora de café implementada.

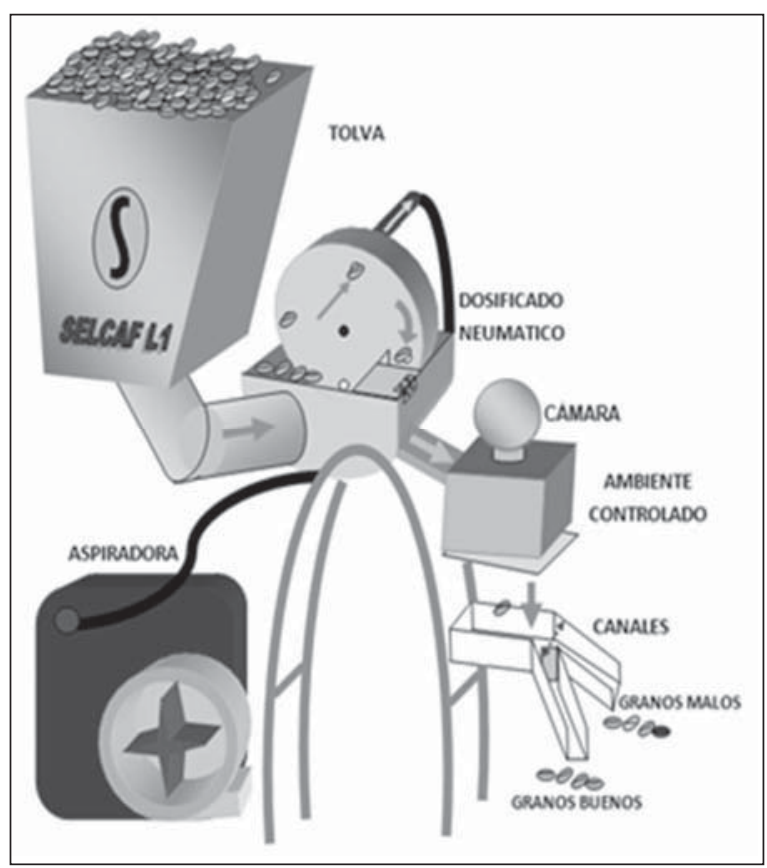

Figura 14. Sistema selector de café en la etapa excelso.

Fuente: elaboración propia
Para analizar los resultados alcanzados por el sistema selector fue necesario contar con la ayuda del experto de la Hacienda Cafetera California, en el municipio de Viota-Cundinamarca, Carlos López, quien, observando los resultados ofrecidos por el sistema, dio su propio concepto con los granos evaluados por el sistema selector.

Para la realización de las pruebas se emplearon 100 granos de café, los cuales fueron seleccionados por el sistema selector, ofreciendo resultados favorables en la identificación de los defectos; al compararlos con el veredicto dado por el experto que los seleccionó manualmente.

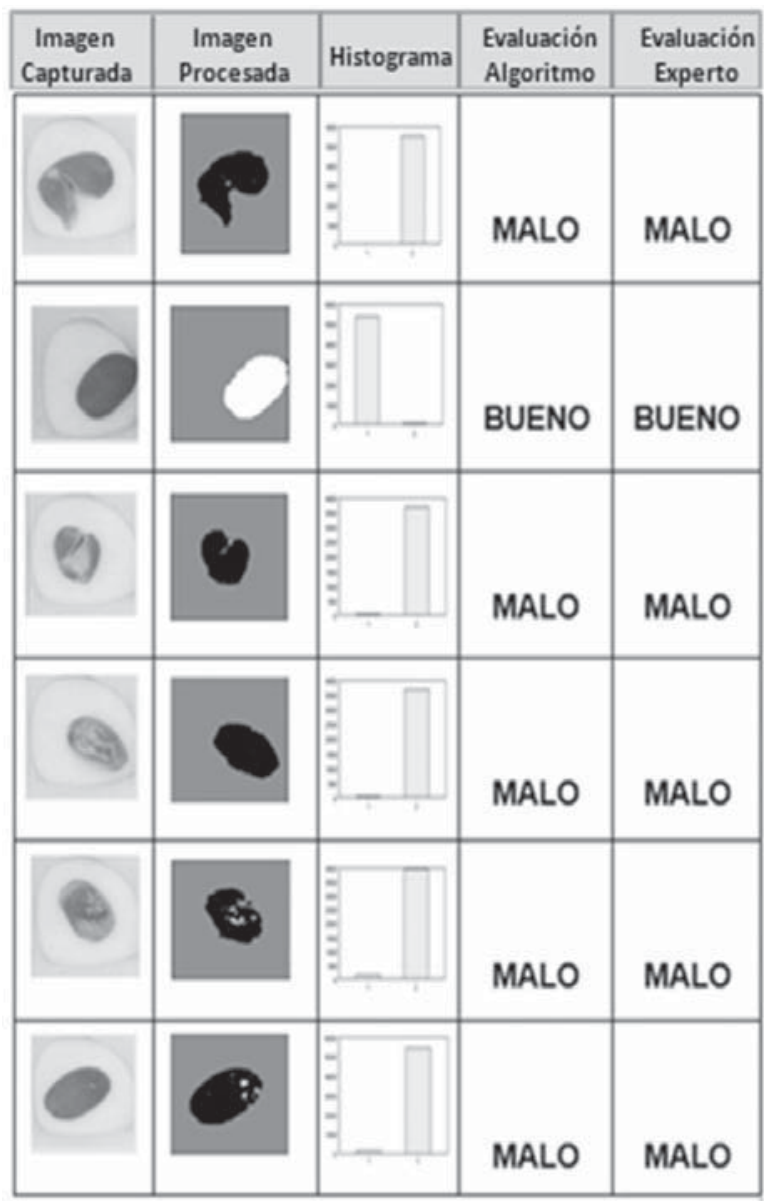

Figura 15. Pruebas y resultados de la evaluación del sistema selector de café.

Fuente: Federación Nacional de Cafeteros de Colombia, Aprenda a vender su café. 
Se encontró que el sistema coincidió de manera favorable con la calificación dada por el experto, en relación a los granos que estaban afectados y a los que estaban buenos, casi en su totalidad; presentando tan sólo un problema con un grano que tenía un grado de daño bastante pequeño y la resolución del sistema no lo tomó, el área afectada de ese grano era inferior al $4 \% \mathrm{y}$, según criterio del experto no era de importancia, pues los granos de café, en su inmensa mayoría, cuando se encuentran con algún defecto, existe una alta tendencia a que se afecte el grano en su totalidad. Por tal motivo, luego de buscar más granos con esta misma característica se determinó que el sistema está en capacidad de seleccionar granos con área afectada superior a un 4\%. Pero según recomendaciones del conocedor del café, lo importante es que reconozca áreas afectadas superiores a un $20 \%$, por consiguiente, el sistema cumple con las expectativas de este experto.

\section{CONCLUSIONES}

Para segmentar por umbrales es necesario una iluminación uniforme en la imagen, puesto que, en esta técnica de segmentación, se establecen unos rangos para los pixeles y los cambios de luz en el ambiente afectan notablemente los resultados de forma negativa. Por ello, es importante el uso de un ambiente controlado que logre garantizar condiciones correctas para la toma de las imágenes.

En las aplicaciones donde se requiera segmentar objetos que no se resaltan con facilidad, y que se encuentran con otros objetos que sí sobresalen, los métodos de segmentación con parámetros fijos logran realizar esta labor satisfactoriamente; al no ajustarse a las regiones más relevantes y limitarse a segmentar lo que se le estipuló como parámetros de trabajo; de acuerdo a los resultados mostrados en el presente trabajo, donde es importante resaltar defectos del grano que tienen gran parecido con las aéreas buenas del grano.

En la segmentación de imágenes por múltiples umbrales, es importante que estos no posean un rango muy grande, porque una ventana de trabajo amplia permitiría que se segmentaran zonas indeseadas, abriendo la posibilidad de que los componentes de la imagen se combinaran de diversas formas obteniendo una segmentación inadecuada.

Para el desarrollo del sistema selector de granos de café se empleó el espacio de color RGB, puesto que tiene una ventana amplia de 0 a 255 valores para cada componente de color, lo que contribuye con la precisión en la segmentación, al momento de generar los rangos de los umbrales, además, este espacio de color lo emplean la mayoría de las cámaras digitales, lo que evita la conversión de la imagen, ahorrando tiempo de ejecución y evitando errores en las aproximaciones al transformar la imagen de un espacio de color a otro.

La selección de la cámara digital empleada para la adquisición de las imágenes cumple un papel importante en el buen desempeño del sistema, puesto que las cámaras poseen sensores de luminosidad que tienen relación proporcional con el contraste y la toma de imágenes con colores reales.

Una ventaja que poseen los métodos de segmentación de parámetros de trabajo fijos y no ajustables, es que en la ejecución de un algoritmo no se necesita iterar en busca de los parámetros para segmentar, sino que se ya vienen integrados; por consiguiente son más rápidos. Pero la desventaja fundamental que tienen estos métodos, al no ser ajustables, es que son diseñados para ciertas condiciones específicas y si estas condiciones cambian un poco no funcionan. 


\section{REFERENCIAS}

[1] Federación Nacional de Cafeteros de Colombia, Cartilla cafetera, Tomo II, Centro Nacional de Investigaciones de Café: Colombia, Octubre de 2004, pp.152-190.

[2] Federación Nacional de Cafeteros de Colombia, Aprenda a vender su café, Colombia, Junio de 2004, pp.10-13.

[3] Procesamiento digital de Imágenes, Departamento de recursos hídricos, Facultad de Ingeniería Agrícola, 2010, [en línea]. Disponible:

http://es.scribd.com/doc/331892/Procesamiento-Digital-de-Imagenes

[4] D. Pascual, Algoritmos de Agrupamiento", Departamento de Computación, Universidad de Oriente, Cuba, 2007, [en línea]. Disponible:

http://marmota.dlsi.uji.es/WebBIB//papers/2007/1_Pascual-MIA-2007.pdf.
[5] C. Cattaneo, L. Larcher y A. Herrera, Segmentación de imágenes mediante umbralizado adaptativo en imágenes de color, Asociación Argentina de Mecánica Computacional, Facultad de Agronomía y Agroindustrias: Universidad Nacional de Santiago de Estero, 2010, [en línea]. Disponible: http://www.amcaonline.org.ar/ojs/index. php/mc/article/viewFile/3440/3357.

[6] C. Pérez, M. A. Vicente, C. Fernández, O. Reinoso, y A. Gil, Aplicación de los diferentes espacios de color para detección y seguimiento de caras, Universidad Miguel Hernández.

[7] V. Haghighatdoost and R. Safabakhsh, “Automatic multilevel color image thresholding by the growing time adaptive self organizing map. Information and Communication Technologies”, ICTTA '06. 2 nd, pp.17681772, 2006. 